\title{
Routine histopathology of gallbladder after elective cholecystectomy for gallstones: waste of resources or a justified act?
}

\author{
Faisal G Siddiqui ${ }^{1}$, Ahmer A Memon ${ }^{1}$, Arshad H Abro ${ }^{1}$, Nazeer A Sasoli ${ }^{1}$ and Lubna Ahmad ${ }^{2}$
}

\begin{abstract}
Background: Selective approach for sending cholecystectomy specimens for histopathology results in missing discrete pathologies such as premalignant benign lesions such as porcelain gallbladder, carcinoma-in-situ, and early carcinomas. To avoid such blunders therefore, every cholecystectomy specimen should be routinely examined histologically. Unfortunately, the practice of discarding gallbladder specimen is standard in most tertiary care hospitals of Pakistan including the primary investigators' own institution. This study was conducted to assess the feasibility or otherwise of performing histopathology in every specimen of gallbladder.
\end{abstract}

Methods: This cohort study included 220 patients with gallstones for cholecystectomy. All cases with known secondaries from gallbladder, local invasion from other viscera, traumatic rupture of gallbladder, gross malignancy of gallbladder found during surgery was excluded from the study. Laparoscopic cholecystectomy was performed in majority of cases except in those cases where anatomical distortion and dense adhesions prevented laparoscopy. All gallbladder specimens were sent for histopathology, irrespective of their gross appearance.

Results: Over a period of two years, 220 patients with symptomatic gallstones were admitted for cholecystectomy. Most of the patients were females (88\%). Ninety two per cent patients presented with upper abdominal pain of varying duration. All specimens were sent for histopathology. Two hundred and three of the specimens showed evidence chronic cholecystitis, 7 acute cholecystitis with mucocele, 3 acute cholecystitis with empyema and one chronic cholecystitis associated with poly. Six gallbladders (2.8\%) showed adenocarcinoma of varying differentiation along with cholelithiasis.

Conclusion: The histopathological spectrum of gallbladder is extremely variable. Incidental diagnosis of carcinoma gall bladder is not rare; if the protocol of routine histopathology of all gallbladder specimens is not followed, subclinical malignancies would fail to be identified with disastrous results. We strongly recommend routine histopathology of all cholecystectomy specimens.

Keywords: Gallbladder malignancy, Cholelithiasis, Cholecystectomy

\section{Background}

Discarding gallbladder specimens without histopathological analysis is best avoided. Selective approach for sending these specimens to the laboratory results in missing discrete pathologies like premalignant benign lesions such as porcelain gallbladder, carcinoma-in-situ and early carcinomas $[1,2]$. Early carcinoma of gallbladder notoriously

\footnotetext{
*Correspondence: faisalgsiddiqui@gmail.com

'Department of Surgery, Liaquat University of Medical \& Health Sciences, Jamshoro 71000, Pakistan

Full list of author information is available at the end of the article
}

remains undiagnosed without histopathology as it neither produces clinical symptoms or signs nor provides any clues on ultrasound assessment. Cholecystectomy performed with provisional diagnosis of benign diseases based on clinical, ultrasonological and computerized tomographic scanning misses a significant number of early malignant lesions of gallbladder. To avoid such blunders with bad consequences, therefore, every cholecystectomy specimen should be routinely examined histologically [3].

Carcinoma gallbladder carries one of the worst of cancer mortality. It is a frequent underlying pathology in

\section{Biomed Central}


patients undergoing surgical intervention for chronic cholecystitis with cholelithiasis [4]; long standing chronic inflammation by gallstones is considered an important etiological role in carcinogenesis. The incidence of carcinoma gallbladder associated with gallstones varies from 0.3 to 12 per cent $[5,6]$. Histopathological analysis is therefore mandatory for diagnosis of early carcinomas. Good prognosis is anticipated in patients with gallbladder carcinoma discovered as an incidental finding in stage I disease [5].

The practice of discarding gallbladder specimen is standard in most tertiary care hospitals of Pakistan including the primary investigator's own institution on the pretext that "surgeon knows best which gallbladder is to be sent to laboratory". Histopathology is restricted to only those specimens, which show gross abnormalities. This practice is based on the assumption that gallbladder carcinoma is always associated with macroscopic abnormalities. At the same time, this selective approach is justified by claiming that it reduces patient's financial liabilities and pathologist's workload. This contradicts to the worldwide practice where gallbladder specimen is invariably sent for histological analysis for the sole purpose of identifying discrete carcinoma in early stage.

This study was conducted to assess the feasibility or otherwise of performing histopathology in every specimen of gallbladder. This would ensure picking of discrete carcinoma of gallbladder, hidden to both the human eyes and touch, which in turn will assist in decreasing mortality rate.

\section{Methods}

This cohort study was carried out at the Department of Surgery, Liaquat University Hospital, Hyderabad/Jamshoro, Pakistan, over a period of two years from March 2010 to February 2012. The study was designed in compliance with the Helsinki Declaration and a formal approval for the study was obtained from the institutional Ethics Review Committee (ERC), Liaquat University of Medical \& Health Sciences.

The study consisted of 220 patients with acute or chronic cholecystitis secondary to gallstones admitted through the outpatient Department. Non-probability convenient sampling technique was used. Written, informed consent was taken from all the participants and/or their next of kin where so applied.

Patients with evidence of carcinoma gallbladder, on clinical grounds and confirmed on ultrasonography and/or CT scan were excluded. Gallbladders showing gross abnormalities suggestive of localized or infiltrative malignancy during surgery were excluded. Detailed history and thorough clinical examination of the patients was done with special attention to the right hypochondrium for preoperative assessment of palpable mass. Systemic review was done to see any co-morbidity. Baseline and specific investigations especially ultrasonography of abdomen was done in all patients. Laparoscopic cholecystectomy was performed in all cases but had to be converted to open procedure in few cases where anatomical distortion and dense adhesions prevented any further progress laparoscopically. All gallbladder specimens, including those with no obvious gross abnormality, were sent for histopathology.

A predesigned proforma was used to put down the information gathered. Data were analyzed using SPSS version 17.0.

\section{Results}

Over a period of two years, two hundred and twenty patients with symptomatic gallstones were admitted for cholecystectomy. There were 193 females and 27 males with a male to female ratio of 1:7. The age ranged from 19 to 80 years with the mean age of $32.3 \pm 5.3$ years (Table 1). Majority of patients (92\%) presented with upper abdominal pain of varying duration. Other symptoms are depicted in Table 2.

All 220 gallbladders were palpated and were opened per-operatively for any focal or diffuse thickening of the gallbladder wall, a raised mucosal plaque, polypoid growth or an infiltrating grey white mass. The specimens were then sent for histopathology. Two hundred and three of the specimens showed evidence chronic cholecystitis, 7 acute cholecystitis with mucocele, 3 acute cholecystitis with empyema and one incidental associated polyp. Six gallbladders $(2.8 \%)$ showed evidence of adenocarcinoma of varying differentiation along with cholelithiasis, (Table 3).

There were six incidental carcinomas with no gross abnormalities in this series. Subsequent staging revealed three adenocarcinomas in stage T1b, two in stages $\mathrm{T} 2$ and one in T3 stage. Three patients with T1 tumors did not undergo any further procedure; three patients with advanced stages (T2 and T3) underwent revision surgery with resection of liver segments $4 \mathrm{~b}$ and 5 (T2) and right hepatectomy (T3) along with lymphadenectomy. Port site rim of about $2 \mathrm{cms}$ were also excised and sent for histopathology and was found to be free of tumor seedling in all three cases.

\section{Table 1 Age distribution*}

\begin{tabular}{lll}
\hline Age of patients (years) & No. of Patients $(\mathbf{n}=\mathbf{2 2 0})$ & $\mathbf{\%}$ \\
\hline $\mathbf{1 9 - 3 0}$ & 54 & 24.6 \\
$\mathbf{3 1 - 4 0}$ & 61 & 27.8 \\
$\mathbf{4 1 - 5 0}$ & 59 & 26.8 \\
$\mathbf{5 1 - 6 0}$ & 34 & 15.4 \\
$\mathbf{6 1 - 7 0}$ & 10 & 4.5 \\
$\mathbf{7 1 - 8 0}$ & 02 & 0.9
\end{tabular}

*Mean age $32.25 \pm 5.3$ years. 
Table 2 Presenting symptoms

\begin{tabular}{lll}
\hline Symptoms & No. of Patients $(\mathbf{n = 2 2 0})$ & \% \\
\hline Pain in Upper abdomen & 201 & 91.4 \\
Intolerance to fatty food & 134 & 61 \\
Nausea and/or vomiting & 44 & 20 \\
Mass in right hypochondrium & 5 & 2.3 \\
\hline
\end{tabular}

\section{Discussion}

In this study, females outnumbered males with male to female ratio of 1:7. Female predominance is also reported by similar studies $[7,8]$. The mean age $32.25 \pm 5.3$ years ranging from 19 to 80 years, slightly higher than that reported in other studies [9].

Over ninety one per cent patients presented with pain upper abdomen, a number significantly lower than that reported by Laghari et al [10]. where all patients had upper abdominal pain. None of the patients in our study had any evidence of malignancy either clinically or on ultrasound examination.

The most common histopathological finding in our study was chronic cholecystitis; 203 (92.3\%) specimens were reported as chronic inflammation with mucosal ulceration, denudation, metaplasia to dysplasia and wall infiltration by chronic inflammatory cells like neutrophils, macrophages, plasma cells and varying degrees of fibrosis. A similar study by Memon [11] also reports chronic cholecystitis as major histopathological finding, identified in $64.8 \%$ cases.

Empyema of the gallbladder is often difficult to distinguish from uncomplicated acute cholecystitis [12]. In this study, $3(1.3 \%)$ cases were reported as acute cholecystitis with empyema of gallbladder. This is in stark contrast to $31.5 \%$ cases of empyema associated with cholecystitis as reported by Memon [11]. Mucocele of the gallbladder has an incidence of 3 percent. In this study, 3.2 cases presented as cholecystitis with mucocele; reported incidence of mucocele is, however, several times higher $[13,14]$.

Gallbladder polyps have an incidence ranging from 4.6 to 6.9 per cent [15]. In our study, one case of gallbladder polyp was identified. This low incidence can be attributed to small number of cases in our series. The only polyp discovered in our study was in a female. However,

Table 3 Histopathological report $(n=220)$

\begin{tabular}{llll}
\hline Histopathology & Male & Female & \% \\
\hline Chronic Cholecystitis & 18 & 185 & 92.3 \\
Acute cholecystitis with mucocele & 5 & 2 & 3.2 \\
Acute cholecystitis with empyema & 2 & 1 & 1.3 \\
Polyp & 0 & 1 & 0.5 \\
Malignancy & 2 & 4 & 2.7 \\
Total & $\mathbf{2 7}$ & $\mathbf{2 0 3}$ & $\mathbf{1 0 0}$ \\
\hline
\end{tabular}

the prevalence of this pathology is much higher amongst males [16].

In our series, incidental carcinoma of gallbladder was found in 6 cases $(2.7 \%)$. These gallbladders showed no gross abnormality per-operatively. The incidence of gallbladder malignancy in this series was considerably low compared to other studies, which show an incidence varying from 6.9 to 12 per cent $[6,17,18]$. The low incidence of malignancy in our series can be attributed to high sensitivity to exclusion criteria, where all patients with any preoperative evidence of malignancy, no matter how trivial, were excluded from the study. Low incidence of malignancy in our patients can also be attributed to increased acceptance and early reporting for laparoscopic cholecystectomy due to resort to day-care surgery at our institution. Samad [3] reports an incidence of $1.1 \%$ of malignancy in patients who underwent cholecystectomy for presumed chronic cholecystitis with cholelithiasis.

All patients in our series presented with longstanding history of chronic cholecystitis. There were no symptoms or signs suggestive of underlying malignancy in any patient; gallbladder malignancy usually does not have any characteristic clinical features with over 90 per cent of patients presenting with symptoms of acute or chronic cholecystitis [19]. Although ultrasound has a high diagnostic accuracy for both advanced and early gallbladder cancer [20], none of the six carcinomas in this series were picked on preoperative ultrasound. In addition, all six gallbladder specimens showed no macroscopic evidence of malignancy when they were opened during surgery. This is in contrast to the study by De Zoyasa et al. in whom all four cancers were suspected either on preoperative ultrasound or grossly during surgery; they suggest a more selective approach to gallbladder histology which may have saved both time and cost without having any unfavorable effects on patients well-being [21]. Similar observations and recommendations are made by other studies [22,23]. The issue of routine histopathology of all gallbladder specimen therefore remains unresolved; the need to send every specimen for histopathology or otherwise therefore depends on the expertise of the ultrasonologist as it depends on the skill of the operating surgeon. We, however, advocate routine histopathology of all gallbladders removed at surgery since the subsequent report would provide evidence of malignancy on solid grounds.

Although there are myriad of premalignant conditions, carcinoma gallbladder has a strong association with gallstones [17]. The strong association between the two warrants attention paid to histopathology of specimen in all cases undergoing cholecystectomy for cholelithiasis, irrespective of presence or otherwise of any gross abnormalities. It is widely reported that long standing mucosal irritation by the stones cause atypical cellular changes and increased cellular proliferation. It has been hypothesized 
that in long standing cases, these areas of hyperplasia progress to metaplasia and carcinoma-in- situ [24]. Studies confirm presence of such changes in the vicinity of gallbladder carcinoma [25]. The incidence of malignancy in our study was $2.7 \%$, which is similar to that reported by Khan AH [26].

Histopathology revealed adenocarcinoma of gallbladder in six patients. One tumor was in stage T1b, two in T2 while one was in stage T3. While Cholecystectomy is an adequate treatment for pT1 tumors, pT2 and pT3 tumors require revision surgery to achieve a tumor-free surgical margin, along with lymph node dissection [27]. Three patients with the unexpected gallbladder cancer in stages $\mathrm{T} 2$ and $\mathrm{T} 3$ underwent a second standard revision procedure including transection of liver segments $4 \mathrm{~b}$ and 5 (T2) and right hepatectomy (T3) with lymphadenectomy. These patients were followed up the oncological department for a period varying from 6 months to one year before being lost to follow up.

All six cases of incidentally diagnosed malignancies had associated gallstones, thereby strongly supporting the role of chronic irritation by long standing gallstones as etiological factor for carcinoma gall bladder.

Grading of cancer was found well differentiated to poorly differentiated adenocarcinoma, no case of squamous cell carcinoma, or other variant of cancerous histopathology seen.

\section{Conclusion}

The histopathological spectrum of gallbladder after cholecystectomy is extremely variable. Incidental diagnosis of carcinoma gallbladder is not rare; we discovered evidence of malignancy in $6(2.8 \%)$ cases on subsequent histopathological examination of gallbladder specimen, which showed no gross features of cancer. These cases had no symptoms suggestive of underlying malignancy nor was cancer reported on any of the preoperative investigations. Had the protocol of routine histopathology of all gallbladder specimens not been followed, these cases would have been failed to identify with disastrous results; We therefore, strongly advocate routine histopathology of all cholecystectomy specimens. Old patients and patients having long duration symptoms are strong candidates for histopathology of gallbladder specimen. The limitations of this study included a small sample size.

\section{Competing interests}

The authors declare that they have no competing interests.

\section{Authors' contributions}

FGS carried out acquisition, analysis, interpretation of the data and drafting of the manuscript. AAM was involved interpretation of the data, drafting of the manuscript, and revised it critically for the intellectual content till the final version was reached. AHA, NAS and LA have read, edited and approved the final manuscript. All authors read and approved the final manuscript.

\section{Acknowledgement}

The authors acknowledge the contribution of Prof. Abdul Sattar Memon, Dean of Surgery \& Allied Sciences, Liaquat University of Medical \& Health Sciences Jamshoro for critical and final revision of the manuscript before its submission. The study was self-funded.

\section{Author details}

'Department of Surgery, Liaquat University of Medical \& Health Sciences, Jamshoro 71000, Pakistan. ${ }^{2}$ Department of Gynea \& Obs, Liaquat University of Medical \& Health Sciences, Jamshoro 71000, Pakistan.

Received: 1 February 2013 Accepted: 5 July 2013

Published: 8 July 2013

\section{References}

1. Underwood JCE: A recovery plan for histopathology. Royal Coll Path Bulletin 2001, 113:12-14.

2. Wilkinson DS: Carcinoma of the gall bladder: an experience and review of the literature. Aust N Z J Surg 1995, 65:724-727.

3. Samad A: Gall bladder carcinoma in patients undergoing cholecystectomy for cholelithiasis. J Pak Med Assoc 2005, 55:497-499.

4. Siddique K, Ali Q, Mirza S, Jamil A, Ehsan A, Latif S, et al: Evaluation of the aetiological spectrum of obstructive jaundice. J Ayub Med Coll Abbottabad 2008, 20(4):62-66.

5. Inui K, Yoshino J, Miyoshi H: Diagnosis of gallbladder tumors. Intern Med 2011, 50(11):1133-1136.

6. Siddiqui FG, Soraya NS: An audit of cholecystectomy specimens. J Surg Pak 2002, 7:18-21.

7. Channa NA, Soomro AM, Ghangro AB: Cholecystectomy is becoming an increasingly common operation in Hyderabad and adjoining areas. Rawal Med J 2007, 32(2):128-130.

8. Murshid KR: Symptomatic gallstones: a disease of young Saudi women. Saudi J Gastroenterol 1998, 4(3):159-162.

9. Ali SA, Tahir SM, Soomoro AG, Siddiqui AJ, Memon AS: Open cholecystectomy without intraperitoneal drainage. J Ayub Med Coll Abbottabad 2010, 22(2):29-31.

10. Laghari AA, Talpur KAH, Malik AM, Khan SA, Memon Al: Laparoscopic Cholecystectomy in complicated gallstone disease. J Liaquat Uni Med Health Sci 2008, 7(1):18-24.

11. Memon W, Khanzada TW, Samad A, Kumar B: Histopathology sepectrum of gallbladder specimens after cholecystectomy. Pak J Med Sci 2011, 27(3):533-536.

12. Malik AM, Khan A, Sheikh U, Sheikh S, Laghari AA, Talpur KA: Changing spectrum of gallstone disease: an experience of 23 cases less than 10 years of age. J Ayub Med Coll Abbottabad 2008, 20(4):34-36.

13. Rosai RJ: Ackerman's Surgical Pathology. Vol 1. 9th edition. New York, NY: Mosby; 2004. 1039

14. Memon MR, Memon SR, Soomro AA, Shah SQA: Experience of laparoscopic cholecystectomy at Sukkur. Med Channel 2010, 16(2):290-294.

15. Matos AS, Baptista HN, Pinheiro C, Martinho F: [Gallbladder polyps: how should they be treated and when?]. Rev Assoc Med Bras 2010, 56(3):318-321.

16. Sun XJ, Shi JS, Han Y, Wang JS, Ren H: Diagnosis and treatment of polypoid lesions of the gallbladder: report of 194 cases. Hepatobiliary Pancreat Dis Int 2004, 3(4):591-594.

17. Ayyaz M, Waris M, Fahim F: Presentation and etiological factors of cancer gall bladder in patients undergoing cholecystectomies at Mayo Hospital, Lahore. Ann King Edward Med Coll 2001, 7:138-140.

18. Nawaz T, Khan RA, Malik AZ, Anwar I, Younus M: Incidence of carcinoma gall bladder in cholelithiasis. Pak J Surg 2000, 16:33-36.

19. Moin M: Mode of presentation of carcinoma of gallbladder. Ann King Edward Med Coll 2000, 10(10):234-235.

20. Kumar A, Aggarwal S, Berry M, Sawhney S, Kapur BM, Bhargava S: Ultrasonography of carcinoma of the gallbladder: an analysis of 80 cases. J Clin Ultrasound 1990, 18(9):715-720.

21. De Zoysa MI, De Silva SK III: Is routine histopathological examination of gallbladder specimens justifiable? Ceylon Med J 2010, 55(1):13-16.

22. Bazoua G, Hamza N, Lazim T: Do we need histology for a normal-looking gallbladder? J Hepatobiliary Pancreat Surg 2007, 14(6):564-568.

23. Darmas B, Mahmud S, Abbas A, Baker AL: Is there any justification for the routine histological examination of straightforward cholecystectomy specimens? Ann R Coll Surg Engl 2007, 89(3):238-241. 
24. Duarte I, Llanos O, Domke H, Harz C, Valdivieso V: Metaplasia and precursor lesions of gallbladder carcinoma. Frequency, distribution, and probability of detection in routine histologic samples. Cancer 1993, 72(6):1878-1884

25. Sarma NH, Ramesh K, Gahukamble LD, Fituri OM, Mangal DK: Gall bladder cancer in north eastern Libya. East Afr Med J 1998, 75(7):417-421.

26. Khan AH, Haroon Ur R, Goraya S: Gallbladder carcinoma; frequency in patients undergoing cholecystectomy for chronic cholecystitis. Professional Med J 2011, 18(1):120-123.

27. Choi $\mathrm{SB}, \mathrm{Hj} \mathrm{H}, \mathrm{Kim} \mathrm{CY}$, et al: Incidental gallbladder cancer diagnosed following laparoscopic cholecystectomy. W J Surg 2009, 33(12):2657-2663.

doi:10.1186/1471-2482-13-26

Cite this article as: Siddiqui et al: Routine histopathology of gallbladder after elective cholecystectomy for gallstones: waste of resources or a justified act? BMC Surgery 2013 13:26.

\section{Submit your next manuscript to BioMed Central and take full advantage of:}

- Convenient online submission

- Thorough peer review

- No space constraints or color figure charges

- Immediate publication on acceptance

- Inclusion in PubMed, CAS, Scopus and Google Scholar

- Research which is freely available for redistribution 